\title{
Variable copy number of mitochondrial DNA (mtDNA) predicts worse prognosis in advanced gastric cancer patients
}

\author{
Guanjun Zhang ${ }^{1 \dagger}$, Yiping Qu ${ }^{2+}$, Siwen Dang ${ }^{2}$, Qi Yang ${ }^{2}$, Bingyin Shi ${ }^{2}$ and Peng $\mathrm{Hou}^{2 *}$
}

\begin{abstract}
Background: Change of mitochondrial DNA (mtDNA) copy number is widely reported in various human cancers, including gastric cancer, and is considered to be an important hallmark of cancers. However, there is remarkably little consensus on the value of variable mtDNA content in the prognostic evaluation of this cancer.

Methods: Using real-time quantitative PCR approach, we examined mtDNA copy number in a cohort of gastric cancers and normal gastric tissues, and explored the association of variable mtDNA content with clinical outcomes of gastric cancer patients.

Results: Our data showed that the majority of gastric cancer patients had low mtDNA content as compared to control subjects although the relative mean mtDNA content was higher in the former than the latter. Moreover, we found that variable mtDNA content was strongly associated with lymph node metastasis and cancer-related death of the patients with late-stage tumors. Notably, variable mtDNA content did not affect overall survival of gastric cancer patients, however, we found that increased mtDNA content was associated with poor survival in the patients with late-stage tumors.

Conclusion: In this study, we demonstrated that variable mtDNA content markedly increased the risk of lymph node metastasis and high mortality of the patients with late-stage tumors. Additionally, we found a strong link between increased mtDNA content and worse survival of the patients with late-stage tumors. Taken together, variable mtDNA content may be a valuable poor prognostic factor for advanced gastric cancer patients.
\end{abstract}

Virtual slides: The virtual slide(s) for this article can be found here: http://www.diagnosticpathology.diagnomx.eu/ vs/1344721463103353.

Keywords: Gastric cancer, Mitochondrial DNA (mtDNA), Copy number, Real-time quantitative PCR, Clinical outcomes

\section{Background}

Gastric cancer is the second cause of cancer deaths after lung cancer, and is a major health burden worldwide [1]. Despite advances in therapeutic modalities during the past decades, the prognosis at the advanced stage is still dismal, with an average 5-year survival rate of less than $20 \%[2,3]$. The cause of gastric cancer is multifactorial, and the prognosis varies widely in gastric cancer patients

\footnotetext{
* Correspondence: phou@mail.xjtu.edu.cn

${ }^{\dagger}$ Equal contributors

${ }^{2}$ Department of Endocrinology, The First Affiliated Hospital of Xi'an Jiaotong University School of Medicine, Xi'an 710061, the People's Republic of China Full list of author information is available at the end of the article
}

due to yet undetermined biologic factors [4]. Thus, there is increasing need to develop reliable biomarkers for predicting clinical outcomes and establishing new therapeutic and preventive strategies to this disease.

Although a number of biomarkers have been demonstrated to be closely associated with poor prognosis of gastric cancer patients [5-9], most of them are concerned with the roles of nuclear DNA (nDNA) alterations in gastric tumorigenesis [10-14]. These genetic or epigenetic alterations cause gain-of-function in oncogenes and lossof-function in tumor suppressor genes [15,16], however,

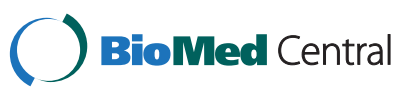

(c) 2013 Zhang et al.; licensee BioMed Central Ltd. This is an open access article distributed under the terms of the Creative Commons Attribution License (http://creativecommons.org/licenses/by/2.0), which permits unrestricted use, distribution, and reproduction in any medium, provided the original work is properly cited. 
relatively less attention has been paid to mitochondrial DNA (mtDNA) alterations. Mitochondria are organelles found in all nucleated cells. The major role of mitochondria is to generate cellular adenosine triphosphate (ATP) through oxidative phosphorylation [17]. Human mtDNA is a 16,569 base-pair, double-stranded, closed-circular DNA molecule that encodes 13 polypeptides, 2 rRNAs, and a set of 22 tRNAs required for protein synthesis in mitochondria [18]. The displacement loop (D-loop) is a noncoding region essential for the replication and transcription of mtDNA. Mutations in the D-loop may cause a reduction in mtDNA copy number or altered mtDNA gene expression $[19,20]$. Generally, each human cell contains several hundred to 1000 mitochondria, and each mitochondrion has 2 to 10 copies of mtDNA. The mitochondrial genome is more vulnerable to oxidative damage and undergoes a higher rate of mutation than does the nDNA [21,22]. Increasing evidences have demonstrated the association of increased mtDNA content in peripheral blood with increased risk of non-Hodgkin lymphoma [22], lung cancer [23], pancreatic cancer [24], breast cancer [25], and colorectal cancer [26], whereas increased risk of renal cancer is associated with decreased mtDNA content [27]. Although several studies have reported depletion in mtDNA copy number in gastric cancers as compared with normal gastric tissues $[28,29]$, there is no relationship between leukocyte mtDNA content and the risk of developing gastric cancer [30]. Until now, the association of mtDNA content with clinical outcomes of gastric cancer patients remains largely unknown.

In the present study, we investigated mtDNA copy number in a cohort of gastric cancers and normal gastric tissues using real-time quantitative PCR approach, and explored the effect of mtDNA content on clinical outcomes of gastric cancer patients.

\section{Methods \\ Patients}

With the approval of our institutional review board and human ethics committee, where required, a total of 103 paraffin-embedded gastric cancer tissues were randomly obtained at the First Affiliated Hospital of Xi'an Jiaotong University School of Medicine between January 2000 and December 2009. A total of 33 gastric tissues from the patients with chronic gastritis who underwent endoscopic biopsy were used as control subjects. None of these patients received chemotherapy and radiotherapy before the surgery. All samples were histologically examined by a senior pathologist at Department of Pathology of the Hospital based on World Health Organization (WHO) criteria. Clinicopathological data were obtained from the patients' files or by interview with the patients or their relatives, and were summarized in Table 1.
Table 1 Clinicopathological characteristics of gastric cancer patients

\begin{tabular}{|c|c|}
\hline Characteristics & No. of patients (\%) \\
\hline \multicolumn{2}{|l|}{ Gender } \\
\hline Male & $84(81.5)$ \\
\hline Female & $19(18.5)$ \\
\hline \multicolumn{2}{|l|}{ Age, years } \\
\hline Mean & 58.8 \\
\hline SD & 12.9 \\
\hline \multicolumn{2}{|l|}{ Tumor localization } \\
\hline gastric cardia & $20(19.4)$ \\
\hline gastric body & $32(31.1)$ \\
\hline gastric antrum & $51(49.5)$ \\
\hline \multicolumn{2}{|l|}{ Tumor size (cm3) } \\
\hline$\leq 3$ & $32(31.1)$ \\
\hline $3-5$ & $36(35.0)$ \\
\hline$>5$ & $35(33.9)$ \\
\hline \multicolumn{2}{|l|}{ Differentiation } \\
\hline well/moderate & $48(46.6)$ \\
\hline poor/undifferentiation & $55(53.4)$ \\
\hline \multicolumn{2}{|l|}{ Tumor invasion } \\
\hline T1 & $23(22.3)$ \\
\hline $\mathrm{T} 2$ & $14(13.6)$ \\
\hline T3 & $52(50.5)$ \\
\hline T4 & $14(13.6)$ \\
\hline \multicolumn{2}{|l|}{ TNM stage } \\
\hline । & $9(8.7)$ \\
\hline$\|$ & $41(39.8)$ \\
\hline III & $47(45.6)$ \\
\hline IV & $6(5.8)$ \\
\hline \multicolumn{2}{|c|}{ Lymph node metastasis (LNM) } \\
\hline Yes & $48(46.6)$ \\
\hline No & $55(53.4)$ \\
\hline \multicolumn{2}{|l|}{ No. of LNM } \\
\hline No & $55(53.4)$ \\
\hline N1 (1-6) & $34(33.0)$ \\
\hline N2 (7-15) & $10(9.7)$ \\
\hline N3 $(\geq 16)$ & $4(3.9)$ \\
\hline \multicolumn{2}{|l|}{ Survival status } \\
\hline Dead & $45(43.7)$ \\
\hline Alive & $58(56.3)$ \\
\hline
\end{tabular}

\section{DNA preparation}

Serial sections from each tumor sample were cut. One section was stained using hematoxylin and eosin (H\&E) and was marked as a tumor representative tissue by an expert surgical pathologist for gastric cancer. Tumor tissues 
Table 2 The primer and TaqMan probe sequences used in this study

\begin{tabular}{lllll}
\hline Genes & $\begin{array}{l}\text { Forward primer } \\
\text { sequence }\left(\mathbf{5}^{\prime} \rightarrow \mathbf{3}^{\prime}\right)\end{array}$ & $\begin{array}{l}\text { Probe } \\
\text { sequence }\left(\mathbf{5}^{\prime} \rightarrow \mathbf{3}^{\prime}\right)\end{array}$ & $\begin{array}{l}\text { Reverse primer } \\
\text { sequence }\left(\mathbf{5}^{\prime} \rightarrow \mathbf{3}^{\prime}\right)\end{array}$ & $\begin{array}{l}\text { Amplification } \\
\text { efficiency }\end{array}$ \\
\hline MT-ND1 & CCCCTAAAACCCGCCACATC & 6FAM-ACCCTCTACATCACCGCCCCGACC-TAMRA & GTAGAAGAGCGATGGTGAGAGC & 93.6 \\
B-actin & TCACCCACACTGTGCCCATCTACGA & 6FAM-ATGCCCTCCCCCATGCCATCC-TAMRA & TCGGTGAGGATCTTCATGAGGTA & 95.7 \\
\hline
\end{tabular}

were then isolated by manual microdissection under an inverted microscope using the marked H\&E section for target tissue identification. DNA was extracted from isolated tumor tissues as previously described [13]. Briefly, the tissues were first treated with xylene for $12 \mathrm{~h}$ at room temperature to remove the paraffin, and were then subjected to digestion with $1 \%$ sodium dodecylsulfate (SDS) and proteinase $\mathrm{K}$ at $48^{\circ} \mathrm{C}$ for 48 to $72 \mathrm{~h}$ with addition of several spiking aliquots of concentrated proteinase $\mathrm{K}$ to facilitate digestion. Genomic DNA was isolated from the digested tissues followed by standard phenol-chloroform extraction and ethanol precipitation protocol, and stored at $-80^{\circ} \mathrm{C}$ until use.

\section{mtDNA copy number analysis}

Relative mtDNA copy number was measured in a cohot of gastric cancers and normal gastric tissues by real-time quantitative PCR method. Specific primers and TaqMan probes were designed using Primer Express 3.0 (Applied Biosystems, Foster City, CA) to amplify MT-ND1 gene in mtDNA and the internal reference gene $\beta$-actin. TaqMan probes were labeled with $5^{\prime}$-FAM (6-carboxyfluorescein, fluorescent reporter) and 3'-TAMRA (6-carboxy-tetramethylrhodamine, fluorescent quencher). The primer and probe sequences for MT-ND1 and $\beta$-actin genes were presented in Table 2. Using a PCR protocol described previously [31], PCR amplification was carried out in the buffer containing $16.6 \mathrm{mM}$ ammonium sulfate, $67 \mathrm{mM}$ Tris base, $2.5 \mathrm{mM} \mathrm{MgCl}_{2}, 10 \mathrm{mM}$ 2-mercaptoethanol, 0.1\% DMSO, $0.2 \mathrm{mM}$ each of dATP, dCTP, dGTP and dTTP, $600 \mathrm{nM}$ each of forward and reverse primers, $200 \mathrm{nM}$ TaqMan probe, 0.6 unit Platinum Taq polymerase and $2 \%$ Rox reference dye. Each sample was run in triplicate, and $\beta$-actin was run in parallel to standardize the input DNA. Standard curves were established using serial dilutions of normal leukocyte DNA with a quantity range of 6.25 to 100 ng per $2 \mu \mathrm{L}$. The relative mtDNA copy number of each sample was calculated as described previously $[27,30]$.

\section{Statistical analysis}

The Mann-Whitney $U$ test was used to compare mtDNA copy number between gastric cancer and normal gastric tissues. Association of mtDNA copy number with clinicopathological characteristics was assessed univariately using the SPSS statistical package (version 11.5, Chicago, IL). Multivariate models were then developed that adjusted for the most important covariates, including age, tumor size, differentiation, and lymph node metastasis. Survival length was determined from the day of primary tumor surgery to the day of death or last clinical follow-up. The Kaplan-Meier method was used for survival analysis grouping with copy number variations of mtDNA. Differences between curves were analyzed using the log-rank test. Multivariate Cox regression analysis was used to evaluate the effect of mtDNA copy number on survival of independently of the number of lymph node metastasis, tumor invasion and differentiation. All statistical analyses were performed using the SPSS statistical package (version 11.5, Chicago, IL). $P$ values $<0.05$ were considered significant.

\section{Results}

\section{Relative mtDNA copy number in gastric cancer}

Real-time quantitative PCR assay was performed to analyze mtDNA copy number in 103 gastric cancers and 33 normal gastric tissues. As shown in Figure 1, the relative mean mtDNA content was higher in gastric cancer patients (6.06 \pm 8.76 copies) than control subjects (4.48 \pm 2.46 copies). However, the difference did not reach statistical significance $(P=0.171)$. The median values among gastric cancer patients and control subjects were 2.94 copies (range $=0.39-50.12$ copies) and 4.07 copies (range $=0.34-10.10$ copies), respectively, suggesting that the majority of gastric cancer patients had low mtDNA

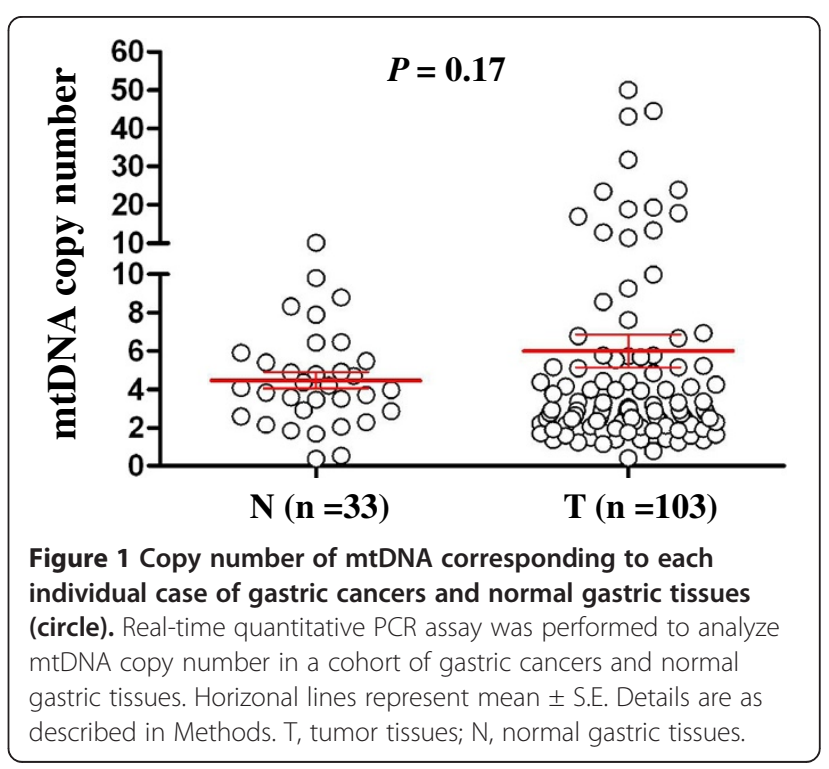


content as compared to control subjects, as supported by the previous studies $[28,29]$. We next evaluated whether mtDNA content differed by selected clinicopathological characteristics. As shown in Figure 2, overall, we did not find significant differences in mtDNA copies by gender, age, tumor localization, tumor size, differentiation, tumor invasion, TNM stage, lymph node metastasis and survival status. Notably, although no statistical significance was noted, the patients with lymph node metastasis had a lower mtDNA content than the patients without lymph node metastasis (4.45 vs. 7.46 copies, $P=0.12$ ) (Figure 2). Moreover, mtDNA content in gastric antrum was lower than that in gastric cardia and body (4.66 vs. 6.51 and 7.99 copies) (Figure 2).

Table 3 Copy number variations of mtDNA in gastric cancer - univariate associations with clinicopathological characteristics

\begin{tabular}{|c|c|c|c|c|}
\hline \multirow[t]{2}{*}{ Characteristics } & \multicolumn{2}{|c|}{ Copy number <3.61 } & \multicolumn{2}{|c|}{ Copy number $>5.35$} \\
\hline & $\mathrm{OR}^{*}(95 \% \mathrm{Cl})$ & $P$ & $\mathrm{OR}^{*}(95 \% \mathrm{Cl})$ & $P$ \\
\hline Male vs. Female & $1.55(0.42-5.70)$ & 0.51 & $1.75(0.37-8.30)$ & 0.48 \\
\hline Age $^{1}$ & $1.00(0.65-1.52)$ & 0.98 & $1.10(0.67-1.79)$ & 0.71 \\
\hline Tumor localization² & $1.11(0.51-2.42)$ & 0.80 & $1.22(0.50-2.99)$ & 0.66 \\
\hline Tumor size ${ }^{3}$ & $1.31(0.66-2.60)$ & 0.45 & $1.37(0.63-3.01)$ & 0.43 \\
\hline Differentiation ${ }^{4}$ & $1.78(0.58-5.49)$ & 0.32 & $1.11(0.31-4.04)$ & 0.87 \\
\hline Tumor invasion ${ }^{5}$ & $0.82(0.46-1.47)$ & 0.50 & $0.69(0.36-1.34)$ & 0.27 \\
\hline TNM stage $^{6}$ & $0.84(0.40-1.78)$ & 0.65 & $0.86(0.36-2.03)$ & 0.73 \\
\hline Lymph node metastasis & $4.93(1.28-19.04)$ & 0.02 & $4.00(0.91-17.58)$ & 0.07 \\
\hline Survival status ${ }^{7}$ & $1.20(0.39-3.73)$ & 0.75 & $1.81(0.50-6.50)$ & 0.37 \\
\hline
\end{tabular}

*OR: odds ratio with $95 \%$ confidence interval; ${ }^{1}$ Age (per 10 years); ${ }^{2}$ Tumor localization (gastric cardia; gastric body; gastric antrum); ${ }^{3} \mathrm{Tumor}$ size $(\leq 3 \mathrm{~cm} ;>3 \mathrm{~cm}$ and $\leq 5 \mathrm{~cm} ;>5 \mathrm{~cm}$ ); ${ }^{4}$ Differentiation (well or moderate; poor or undifferentiation); ${ }^{5}$ Tumor invasion (T1; T2; T3; T4); ${ }^{6} \mathrm{TNM}$ stage (I; II; III; IV); ${ }^{7}$ Survival status (Alive vs. Dead). The cases with 3.61-5.35 mtDNA copies were used as reference. 
Table 4 Copy number variations of mtDNA in early-stage gastric cancer - univariate associations with clinicopathological characteristics

\begin{tabular}{|c|c|c|c|c|}
\hline \multirow[t]{2}{*}{ Characteristics } & \multicolumn{2}{|c|}{ Copy number $<3.61$} & \multicolumn{2}{|c|}{ Copy number $>5.35$} \\
\hline & $\mathrm{OR}^{*}(95 \% \mathrm{Cl})$ & $P$ & $\mathrm{OR}^{*}(95 \% \mathrm{Cl})$ & $P$ \\
\hline Male vs. Female & $1.16(0.11-12.13)$ & 0.90 & $0.80(0.06-11.30)$ & 0.87 \\
\hline $\mathrm{Age}^{1}$ & $0.48(0.05-4.65)$ & 0.53 & $0.20(0.02-2.39)$ & 0.20 \\
\hline Tumor localization ${ }^{2}$ & $3.65(0.91-14.64)$ & 0.07 & $2.78(0.59-13.0)$ & 0.19 \\
\hline Tumor size $^{3}$ & $0.80(0.24-2.65)$ & 0.71 & $0.56(0.13-2.32)$ & 0.42 \\
\hline Tumor invasion ${ }^{4}$ & $0.49(0.16-1.49)$ & 0.21 & $0.28(0.08-0.99)$ & 0.049 \\
\hline Lymph node metastasis & $1.09(0.17-6.85)$ & 0.93 & $0.86(0.10-7.51)$ & 0.90 \\
\hline Survival status ${ }^{5}$ & $0.42(0.07-2.43)$ & 0.33 & $0.25(0.03-2.32)$ & 0.22 \\
\hline
\end{tabular}

*OR: odds ratio with $95 \%$ confidence interval; ${ }^{1}$ Age (per 10 years); ${ }^{2}$ Tumor localization (gastric cardia; gastric body; gastric antrum); ${ }^{3}$ Tumor size ( $\leq 3 \mathrm{~cm}$; $>3 \mathrm{~cm}$ and $\leq 5 \mathrm{~cm} ;>5 \mathrm{~cm}$ ); ${ }^{4}$ Tumor invasion (T1; T2; T3; T4); ${ }^{5}$ Survival status (Alive vs. Dead). The cases with 3.61-5.35 mtDNA copies were used as reference.

\section{Association of variable mtDNA content with} clinicopathological characteristics of gastric cancer patients To further examine the relationship of mtDNA content with clinicopathological characteristics of gastric cancer patients, we chosed two cutoff points, which are the lower and upper limit (3.61 and 5.35 copies) of the overall 95\% confidence interval for all control subjects, respectively. Gastric cancer patients were then categorized into three groups by use of these two cutoff points, including individuals with highest ( $>5.35$ copies) (termed "increased mtDNA content" hereafter), medium (3.61-5.35 copies) and lowest ( $<3.61$ copies) (termed "decreased mtDNA content" hereafter) category of mtDNA content. Medium category of mtDNA content (3.61-5.35 copies) was used as a reference. As shown in Table 3, variable mtDNA content was closely associated with lymph node metastasis in gastric cancer patients. Compared with the reference, decreased mtDNA content significantly increased the risk of lymph node metastasis in gastric cancer patients $(\mathrm{OR}=4.93$, 95\% CI $=1.28-19.04, P=0.02)$. Similarly, although the association did not reach statistical difference, increased mtDNA content also increased the risk of lymph node metastasis of patients $(\mathrm{OR}=4.00,95 \% \mathrm{CI}=0.91$ 17.58, $P=0.07)$.
Gastric cancer patients were further categorized into two groups based on TNM stage, such as individuals with early-stage (stages I and II) and late-stage (stages III and IV) tumors. As shown in Table 4, increased mtDNA content was significantly negatively associated with tumor invasion in the patients with early-stage tumors $(\mathrm{OR}=0.28$, 95\% CI $=0.08-0.99, P=0.049)$. Both decreased and increased mtDNA content dramatically increased the risk of lymph node metastasis for the patients with late-stage tumors (the former: $\mathrm{OR}=27.00,95 \% \mathrm{CI}=2.89-252.62$, $P=0.004$; the latter: $\mathrm{OR}=13.50,95 \% \mathrm{CI}=1.34-135.98$, $P=0.03$ ) (Table 5). Also shown in Table 5, increased mtDNA content was significantly associated with higher mortality of the patients with late-stage tumors $(\mathrm{OR}=6.42$, 95\% CI =1.09-37.74, $P=0.04$ ) (Table 5). Moreover, decreased mtDNA also increased the risk of caner-related death in advanced gastric cancer patients $(\mathrm{OR}=3.11,95 \% \mathrm{CI}=0.66$ $14.60, P=0.15$ ), although no statistical significance was found. In order to assess the independent association of variable mtDNA content with age, tumor size, differentiation and lymph node metastasis, we conducted a multivariable logistic regression. As shown in Table 6, similar to univariate analysis, both decreased and increased mtDNA content remained closely associated with lymph

Table 5 Copy number variations of mtDNA in late-stage gastric cancer - univariate associations with clinicopathological characteristics

\begin{tabular}{|c|c|c|c|c|}
\hline \multirow[t]{2}{*}{ Characteristics } & \multicolumn{2}{|c|}{ Copy number <3.61 } & \multicolumn{2}{|c|}{ Copy number $>5.35$} \\
\hline & $\mathrm{OR}^{*}(95 \% \mathrm{Cl})$ & $P$ & OR $^{*}(95 \% \mathrm{Cl})$ & $P$ \\
\hline Male vs. Female & $1.57(0.31-7.99)$ & 0.59 & $2.79(0.37-20.82)$ & 0.32 \\
\hline Age $^{1}$ & $0.67(0.15-2.89)$ & 0.59 & $1.33(0.25-7.01)$ & 0.73 \\
\hline Tumor localization² & $0.44(0.13-1.45)$ & 0.18 & $0.70(0.19-2.616)$ & 0.60 \\
\hline Tumor size ${ }^{3}$ & $1.86(0.78-4.42)$ & 0.16 & $2.10(0.79-5.57)$ & 0.14 \\
\hline Tumor invasion ${ }^{4}$ & $1.13(0.53-2.41)$ & 0.74 & $1.16(0.50-2.69)$ & 0.73 \\
\hline Lymph node metastasis & $27.00(2.89-252.62)$ & 0.004 & 13.50 (1.34-135.98) & 0.03 \\
\hline Survival status ${ }^{5}$ & $3.11(0.66-14.60)$ & 0.15 & $6.42(1.09-37.74)$ & 0.04 \\
\hline
\end{tabular}

${ }^{*}$ OR: odds ratio with $95 \%$ confidence interval; ${ }^{1}$ Age (per 10 years); ${ }^{2}$ Tumor localization (gastric cardia; gastric body; gastric antrum); ${ }^{3} \mathrm{Tumor}$ size ( $\leq 3 \mathrm{~cm} ;>3 \mathrm{~cm}$ and $\leq 5 \mathrm{~cm} ;>5 \mathrm{~cm}) ;{ }^{4}$ Tumor invasion (T1; T2; T3; T4); ${ }^{5}$ Survival status (Alive vs. Dead). The cases with 3.61-5.35 mtDNA copies were used as reference. 
Table 6 Copy number variations in gastric cancer - multivariable models assessing age, tumor size, differentiation and lymph node metastasis

\begin{tabular}{|c|c|c|c|c|}
\hline \multirow[t]{2}{*}{ Characteristics } & \multicolumn{2}{|c|}{ Copy number <3.61 } & \multicolumn{2}{|c|}{ Copy number $>5.35$} \\
\hline & $\mathrm{OR}^{*}(95 \% \mathrm{Cl})$ & $P$ & $\mathrm{OR}^{*}(95 \% \mathrm{Cl})$ & $P$ \\
\hline $\mathrm{Age}^{1}$ & $0.80(0.49-1.31)$ & 0.38 & $0.96(0.56-1.65)$ & 0.89 \\
\hline Tumor size ${ }^{2}$ & $0.91(0.43-1.92)$ & 0.80 & $1.04(0.46-2.36)$ & 0.92 \\
\hline Differentiation $^{3}$ & $3.00(0.86-10.47)$ & 0.08 & $1.56(0.39-6.19)$ & 0.53 \\
\hline Lymph node metastasis & $7.63(1.63-35.69)$ & 0.01 & $4.41(0.84-23.12)$ & 0.08 \\
\hline
\end{tabular}

*OR: odds ratio with $95 \%$ confidence interval; ${ }^{1}$ Age (per 10 years); ${ }^{2}$ Tumor size $(\leq 3 \mathrm{~cm} ;>3 \mathrm{~cm}$ and $\leq 5 \mathrm{~cm} ;>5 \mathrm{~cm}) ;{ }^{3}$ Differentiation (well or moderate; poor or undifferentiation). The cases with 3.61-5.35 mtDNA copies were used as reference.

node meatstasis after adjustment, particularly the former (OR $=7.63,95 \% \mathrm{CI}=1.63-35.69, P=0.01)$. Moreover, although we did not find statistical significance, deceased mtDNA content was positively associated with poor differentiation of gastric cancer patients $(\mathrm{OR}=3.00$, 95\% CI =0.86-10.47, $P=0.08$ ) (Table 6).

\section{Effect of variable mtDNA content on poor survival of} gastric cancer patients

Given that variable mtDNA content is associated with some of clinicopathological features in gastric cancer patients, we next investigated its association with poor survival. Similarly, medium category of mtDNA content (3.61-5.35 copies) was used as a reference in this study. As shown in Table 7, variable mtDNA content did not affect overall survival of gastric cancer patients. We then used Kaplan-Meier survival curves to further determine the effect of variable mtDNA content on the survival of gastric cancer patients. Similar to the findings in Table 7, decreased or increased mtDNA content did not significantly affect survival time of gastric cancer patients (the former: 54.2 months vs. 51.4 months on average, $P=0.93$; the latter: 44.4 months $v s$. 51.4 months on average, $P=0.38$ ) (Figure 3). Cox multivariate repression showed that decreased or increased mtDNA content (the former: $\mathrm{HR}=0.52,95 \% \mathrm{CI}=0.20-1.38, P=0.19$; the latter: $\mathrm{HR}=1.07$, $95 \% \mathrm{CI}=0.37-3.07, P=0.90$ ) is not a predictor of poor survival for gastric cancer patients as an independently variable with respect to the number of lymph node metastasis, tumor invasion and differentiation. The data were stratified further based on the TNM tumor stage, because it is an independent risk factor for gastric cancer patients. Also shown in Figure 3, decreased or increased mtDNA content did not affect survival time

Table 7 Prognostic value of clinicopathological factors and copy number variation of mtDNA in univariate and multivariate Cox regression analysis $(n=103)$

\begin{tabular}{|c|c|c|c|c|}
\hline \multirow[b]{2}{*}{ Variable } & \multicolumn{2}{|c|}{ Univariate analysis } & \multicolumn{2}{|c|}{ Multivariate analysis } \\
\hline & Hazard ratio $(95 \% \mathrm{Cl})$ & $P$ & Hazard ratio $(95 \% \mathrm{Cl})$ & $P$ \\
\hline \multicolumn{5}{|l|}{ Copy number } \\
\hline $3.61 \sim 5.35$ & 1.00 (reference) & & 1.00 (reference) & \\
\hline$<3.61$ & $1.51(0.44-2.57)$ & 0.90 & $0.52(0.20-1.38)$ & 0.19 \\
\hline$>5.35$ & $1.53(0.58-4.02)$ & 0.39 & $1.07(0.37-3.07)$ & 0.90 \\
\hline \multicolumn{5}{|c|}{ The number of lymph node metastasis } \\
\hline 0 & 1.00 (reference) & & 1.00 (reference) & \\
\hline $1 \sim 6$ & $6.86(3.18-14.91)$ & $<0.001$ & 7.28 (2.87-18.49) & $<0.001$ \\
\hline $7 \sim 15$ & $6.41(2.70-15.25)$ & $<0.001$ & $4.68(1.65-13.28)$ & 0.004 \\
\hline$\geq 16$ & $16.75(5.05-55.56)$ & $<0.001$ & $13.21(3.33-52.45)$ & $<0.001$ \\
\hline \multicolumn{5}{|l|}{ Tumor invasion } \\
\hline T1 & 1.00 (reference) & & 1.00 (reference) & \\
\hline $\mathrm{T} 2$ & $0.85(0.16-4.67)$ & 0.86 & $0.63(0.11-3.54)$ & 0.60 \\
\hline T3 & $4.36(1.53-12.42)$ & 0.006 & $1.51(0.46-4.92)$ & 0.49 \\
\hline T4 & $2.66(1.30-5.48)$ & 0.001 & $3.33(0.92-12.14)$ & 0.07 \\
\hline \multicolumn{5}{|l|}{ Differentiation } \\
\hline Well/moderate & 1.00 (reference) & & 1.00 (reference) & \\
\hline Poor/undifferentiation & $2.22(1.19-4.19)$ & 0.01 & $1.82(0.86-3.82)$ & 0.12 \\
\hline
\end{tabular}




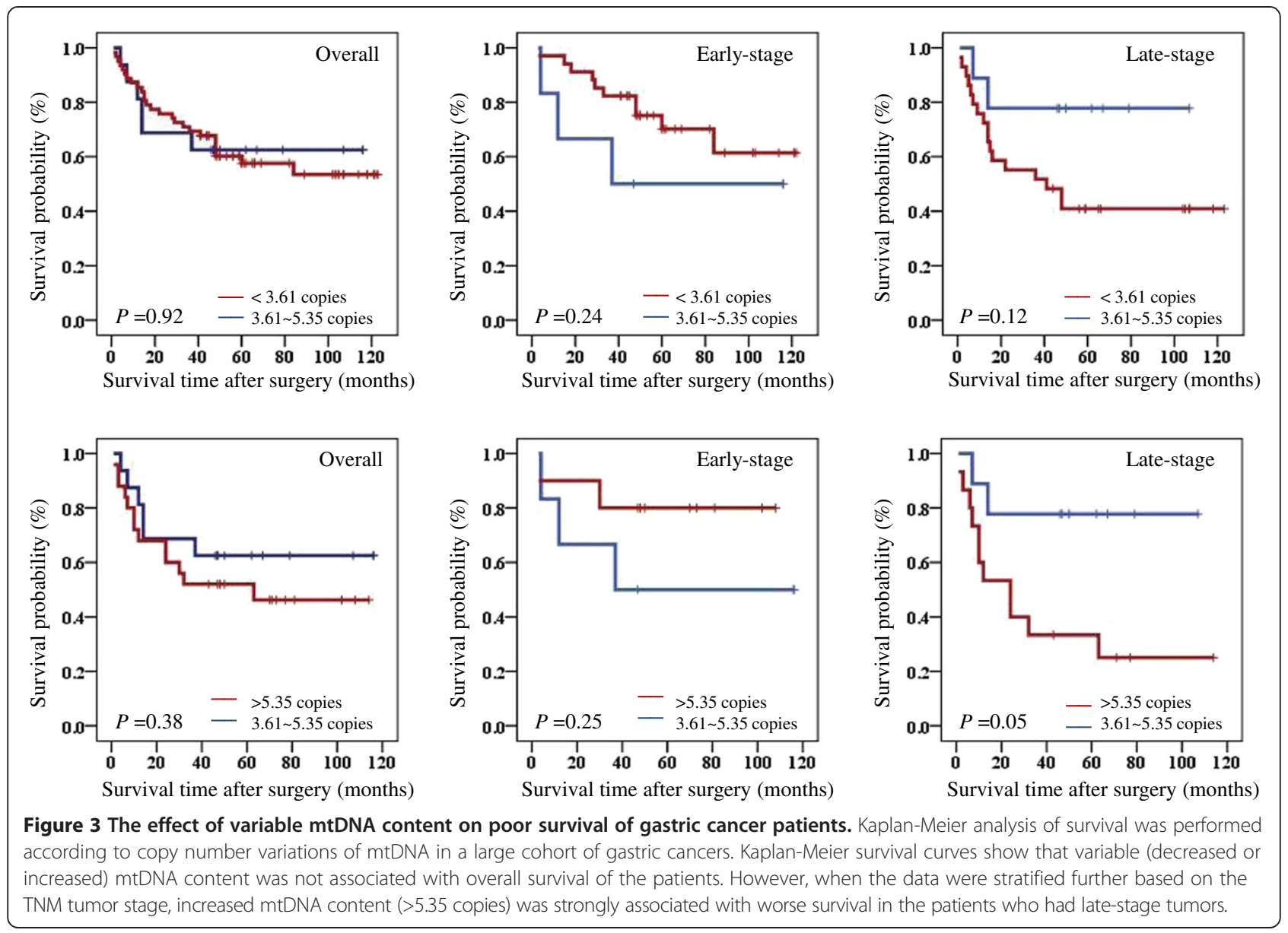

of the patients with early-stage tumors (the former: 60.6 months vs. 55.3 months on average, $P=0.24$; the latter: 61.2 months vs. 55.3 months on average, $P=0.25$ ). However, increased mtDNA content was markedly associated with poor survival of the patients with late-stage tumors as compared with the reference (33.1 months $v s$. 49.3 months on average, $P=0.05$ ) (Figure 3 ).

\section{Discussion}

Although much of the current funding is aligned to continuing to further understand the functional details of the nuclear genome, the mitochondrion and its modest complement of DNA and protein is emerging as a crucial component of the biological networking of nuclear pathways [18]. Mitochondria are eukaryotic organelles involved in many important physiological processes, including metabolism, signaling, apoptosis, cell cycle, differentiation and responsible for energy production [32]. It has been well documented that the enhanced production of mitochondrial reactive oxygen species (ROS), most notably superoxide, hydroxyl radicals, and hydrogen peroxide is a prominent byproduct of cancer cell metabolism [33]. Within various cells, tissues and organs,
mtDNA copy number is different, and this difference can also occur in a given type of cell under different conditions or internal or external microenvironments $[34,35]$. Unlike nuclear DNA, mtDNA is present at a consistently high level in each cell [36], and mtDNA mutation rate is much higher than that of nuclear DNA $[18,21]$. Mitochondrial aberrants, including mtDNA mutations and copy number variations, have been frequently identified in different types of human cancers, including gastric cancer [28-30,36,37], suggesting that mtDNA aberrations play a critical role in gastric tumorigenesis. However, the prognostic values of mtDNA aberrants, particularly copy number variations, in gastric cancer patients ramain largely unclear.

In this study, we investigated relative mtDNA copy number in a cohort of gastric cancers and normal gastric tissues (control subjects) using real-time quantitative PCR approach. Our data showed that the majority of the cancer patients had low levels of mtDNA copy number as compared to control subjects, although mean mtDNA content was a little bit higher in gastric cancer patients than control subjects. In line with this study, the previous studies have demonstrated that mtDNA depletion is 
frequently found in gastric cancers as compared with normal gastric tissues $[28,29]$, implicating that low mtDNA content is involved in the formation and progression of gastric cancer. Moreover, we did not find the association of mtDNA content with most of clinicopathological features, such as gender, age, tumor localization, tumor size, differentiation, tumor invasion, TNM stage and survival status. However, we found that the patients with lymph node metastasis had a lower mtDNA copy number than the patients without lymph node metastasis, although the difference between two groups was not statistically significant.

To further explore the association of mtDNA content with clinicopathological characteristics and poor survival of gastric cancer patients, we categorized the patients into three groups based on two cutoff points (the lower and upper limit of 95\% confidence interval for all control subjects), such as decreased mtDNA content $(<3.61$ copies), normal mtDNA content or reference (3.61-5.35 copies) and increased mtDNA content ( $>5.35$ copies). Our findings showed that variable mtDNA content (whatever decreased or increased mtDNA content) was closely associated with an increased risk of lymph node metastasis for gastric cancer patients as compared to reference. Strikingly, when gastric cancer patients were further categorized into early-stage and late-stage groups based on TNM stage, variable mtDNA content was not asscoiated with lymph node metastasis for the patients with early-stage tumors. However, both decreased and increased mtDNA content significantly increased the risk of of lymph node metastasis for the patients with late-stage tumors. These observations suggest that copy number variations of mtDNA may be invloved in gastric cancer progression. Similar to our findings in the present study, a previous study showed that mtDNA content was increased gradually from the non-cancerous esophageal mucosa to esophageal squamous cell carcinoma (ESCC) and then the metastatic lymph nodes [38]. Moreover, our data showed that variable mtDNA content was associated with cancer-related death of the patients with late-stage tumors. Collectively, our findings suggest that variable mtDNA content may contribute to poor clinical outcomes of gastric cancer patients, particularly the patients with advanced tumors. Next, we evaluated the effect of variable mtDNA content on poor survival of gastric cancer patients. Our data showed that both decreased and increased mtDNA content were not associated with overall survival of gastric cancer patients. However, when the patients were categorized into early-stage and late-stage tumor groups, increased mtDNA content was strongly associated with poor survival in the latter, but not in the former, as supported by a previous study that high mtDNA copy number may contribute to the high bioenergetic function of mitochondria and further confer an advantage for malignant behaviors of cancer cells, such as tumor invasion [39].

\section{Conclusion}

In summary, we investigated relative mtDNA content in a large cohort of gastric cancers, and demonstrated that variable mtDNA content was closely associated with lymph node metastasis and higher mortality of the patients with late-stage tumors. Moreover, increased mtDNA content predicts worse survival for the patients with late-stage tumors. Thus, variable mtDNA content may be a valuable biomarker in evaluating poor prognosis of advanced gastric cancer patients.

\section{Competing interests}

The authors declare that they have no competing interests.

\section{Authors' contributions}

$\mathrm{PH}$ conceived and designed the experiments. GZ, YQ and SD performed the experiments. GZ and QY collected the samples and analyzed the data. $\mathrm{BS}$ and $\mathrm{PH}$ contributed reagents/materials/analysis tools. $\mathrm{PH}$ Wrote the paper. All authors are in agreement with the content of the manuscript and this submission.

\section{Acknowledgements}

This work was supported by the National Key Program for Developing Basic Research (No. 2010CB933903), the National Natural Science Foundation of China (No. 81171969), the Fundamental Research Funds for the Central Universities, and the Program for New Century Excellent Talents in University (No. NCET-10-0674).

\section{Author details}

'Department of Pathology, The First Affiliated Hospital of Xi'an Jiaotong University School of Medicine, Xi'an 710061, the People's Republic of China. ${ }^{2}$ Department of Endocrinology, The First Affiliated Hospital of Xi'an Jiaotong University School of Medicine, Xi'an 710061, the People's Republic of China.

Received: 16 July 2013 Accepted: 11 October 2013

Published: 21 October 2013

\section{References}

1. Jemal A, Bray F, Center MM, Ferlay J, Ward E, Forman D: Global cancer statistics. CA Cancer J Clin 2011, 61:69-90.

2. Blakely AM, Miner TJ: Surgical considerations in the treatment of gastric cancer. Gastroenterol Clin North Am 2013, 42:337-357.

3. Tan VP, Wong BC: Gastric cancer chemoprevention: the current evidence. Gastroenterol Clin North Am 2013, 42:299-316.

4. Allgayer $\mathrm{H}$, Heiss MM, Schildberg FW: Prognostic factors in gastric cancer. Br J Surg 1997, 84:1651-1664.

5. Sotoudeh K, Hashemi F, Madjd Z, Sadeghipour A, Molanaei S, Kalantary E: The clinicopathologic association of c-MET overexpression in Iranian gastric carcinomas; an immunohistochemical study of tissue microarrays. Diagn Pathol 2012, 7:57.

6. Yamaguchi T, Fujimori T, Tomita S, Ichikawa K, Mitomi H, Ohno K, Shida Y, Kato $\mathrm{H}$ : Clinical validation of the gastrointestinal NET grading system: Ki67 index criteria of the WHO 2010 classification is appropriate to predict metastasis or recurrence. Diagn Pathol 2013, 8:65.

7. Liu X, Xiong H, Li J, He Y, Yuan X: Correlation of hK6 expression with tumor recurrence and prognosis in advanced gastric cancer. Diagn Pathol 2013, 8:62.

8. Shan L, Ying J, Lu N: HER2 expression and relevant clinicopathological features in gastric and gastroesophageal junction adenocarcinoma in a Chinese population. Diagn Pathol 2013, 8:76.

9. Yasui W, Oue N, Aung PP, Matsumura S, Shutoh M, Nakayama H: Molecularpathological prognostic factors of gastric cancer: a review. Gastric Cancer 2005, 8:86-94 
10. Corso G, Velho S, Paredes J, Pedrazzani C, Martins D, Milanezi F, Pascale V, Vindigni C, Pinheiro H, Leite M, Marrelli D, Sousa S, Carneiro F, Oliveira C, Roviello F, Seruca R: Oncogenic mutations in gastric cancer with microsatellite instability. Eur J Cancer 2011, 47:443-451.

11. Yao D, Shi J, Shi B, Wang N, Liu W, Zhang G, Ji M, Xu L, He N, Hou P. Quantitative assessment of gene methylation and their impact on clinical outcome in gastric cancer. Clin Chim Acta 2012, 413:787-794.

12. Qu Y, Dang S, Hou P: Gene methylation in gastric cancer. Clin Chim Acta 2013, 424C:53-65.

13. Shi J, Yao D, Liu W, Wang N, Lv H, Zhang G, Ji M, Xu L, He N, Shi B, Hou P. Highly frequent PIK3CA amplification is associated with poor prognosis in gastric cancer. BMC Cancer 2012, 12:50.

14. Shi J, Yao D, Liu W, Wang N, Lv H, He N, Shi B, Hou P, Ji M: Frequent gene amplification predicts poor prognosis in gastric cancer. Int J Mol Sci 2012, 13:4714-4726.

15. Yasui W, Oue N, Kuniyasu H, Ito R, Tahara E, Yokozaki H: Molecular diagnosis of gastric cancer: present and future. Gastric Cancer 2001, 4:113-121.

16. Yokozaki H, Yasui W, Tahara E: Genetic and epigenetic changes in stomach cancer. Int Rev Cytol 2001, 204:49-95.

17. Hatefi Y: The mitochondrial electron transport and oxidative phosphorylation system. Annu Rev Biochem 1985, 54:1015-1069.

18. Wallace DC: Mitochondria and cancer. Nat Rev Cancer 2012, 12:685-698

19. Shadel GS: Expression and maintenance of mitochondrial DNA: new insights into human disease pathology. Am J Pathol 2008, 172:1445-1456.

20. Chinnery PF, Hudson G: Mitochondrial genetics. Br Med Bull 2013, 106:135-159.

21. Copeland WC, Wachsman JT, Johnson FM, Penta JS: Mitochondrial DNA alterations in cancer. Cancer Invest 2002, 20:557-569.

22. Lan Q, Lim U, Liu CS, Weinstein SJ, Chanock S, Bonner MR, Virtamo J, Albanes $\mathrm{D}$, Rothman N: A prospective study of mitochondrial DNA copy number and risk of non-Hodgkin lymphoma. Blood 2008, 112:4247-4249.

23. Hosgood HD 3rd, Liu CS, Rothman N, Weinstein SJ, Bonner MR, Shen M, Lim U, Virtamo J, Cheng WL, Albanes D, Lan Q: Mitochondrial DNA copy number and lung cancer risk in a prospective cohort study. Carcinogenesis 2010, 31:847-849.

24. Lynch SM, Weinstein SJ, Virtamo J, Lan Q, Liu CS, Cheng WL, Rothman N Albanes D, Stolzenberg-Solomon RZ: Mitochondrial DNA copy number and pancreatic cancer in the alpha-tocopherol beta-arotene cancer prevention study. Cancer Prev Res (Phila) 2011, 4:1912-1919.

25. Shen J, Platek M, Mahasneh A, Ambrosone CB, Zhao H: Mitochondrial copy number and risk of breast cancer: a pilot study. Mitochondrion 2010, 10:62-68.

26. Qu F, Liu X, Zhou F, Yang H, Bao G, He X, Xing J: Association between mitochondrial DNA content in leukocytes and colorectal cancer risk: a case-control analysis. Cancer 2011, 117:3148-3155.

27. Xing J, Chen M, Wood CG, Lin J, Spitz MR, Ma J, Amos Cl, Shields PG, Benowitz NL, Gu J, de Andrade M, Swan GE, Wu X: Mitochondrial DNA content: its genetic heritability and association with renal cell carcinoma. J Natl Cancer Inst 2008, 100:1104-1112.

28. Wu CW, Yin PH, Hung WY, Li AF, Li SH, Chi CW, Wei YH, Lee HC: Mitochondrial DNA mutations and mitochondrial DNA depletion in gastric cancer. Genes, Chromosomes Cancer 2005, 44:19-28.

29. Lee HC, Yin PH, Lin JC, Wu CC, Chen CY, Wu CW, Chi CW, Tam TN, Wei YH: Mitochondrial genome instability and mtDNA depletion in human cancers. Ann N Y Acad Sci 2005, 1042:109-122

30. Liao LM, Baccarelli A, Shu XO, Gao YT, Ji BT, Yang G, Li HL, Hoxha M, Dioni L, Rothman N, Zheng W, Chow WH: Mitochondrial DNA copy number and risk of gastric cancer: a report from the Shanghai Women's Health Study. Cancer Epidemiol Biomarkers Prev 2011, 20:1944-1949.

31. Hou P, Liu D, Shan Y, Hu S, Studeman K, Condouris S, Wang Y, Trink A, El-Naggar AK, Tallini G, Vasko V, Xing M: Genetic alterations and their relationship in the phosphatidylinositol 3-kinase/Akt pathway in thyroid cancer. Clin Cancer Res 2007, 13:1161-1170.

32. Wallace DC: A mitochondrial paradigm of metabolic and degenerative diseases, aging, and cancer: a dawn for evolutionary medicine. Annu Rev Genet 2005, 39:359-407.

33. Verschoor ML, Ungard R, Harbottle A, Jakupciak JP, Parr RL, Singh G: Mitochondria and cancer: past, present, and future. Biomed Res Int 2013, 2013:612369.

34. Robin ED, Wong R: Mitochondrial DNA molecules and virtual number of mitochondria per cell in mammalian cells. J Cell Physiol 1988, 136:507-513.
35. Clay Montier LL, Deng JJ, Bai Y: Number matters: control of mammalian mitochondrial DNA copy number. J Genet Genomics 2009, 36:125-131.

36. Burgart $\sqcup$, Zheng J, Shu Q, Strickler JG, Shibata D: Somatic mitochondrial mutation in gastric cancer. Am J Pathol 1995, 147:1105-1111.

37. Tamura G, Nishizuka S, Maesawa C, Suzuki Y, Iwaya T, Sakata K, Endoh Y, Motoyama T: Mutations in mitochondrial control region DNA in gastric tumours of Japanese patients. Eur J Cancer 1999, 35:316-319.

38. Lin CS, Chang SC, Wang LS, Chou TY, Hsu WH, Wu YC, Wei YH: The role of mitochondrial DNA alterations in esophageal squamous cell carcinomas. J Thorac Cardiovasc Surg 2010, 139:189-197.

39. Lin CS, Lee HT, Lee SY, Shen YA, Wang LS, Chen YJ, Wei YH: High mitochondrial DNA copy number and bioenergetic function are associated with tumor invasion of esophageal squamous cell carcinoma cell lines. Int J Mol Sci 2012, 13:11228-11246.

doi:10.1186/1746-1596-8-173

Cite this article as: Zhang et al:: Variable copy number of mitochondrial DNA (mtDNA) predicts worse prognosis in advanced gastric cancer patients. Diagnostic Pathology 2013 8:173.

\section{Submit your next manuscript to BioMed Central and take full advantage of:}

- Convenient online submission

- Thorough peer review

- No space constraints or color figure charges

- Immediate publication on acceptance

- Inclusion in PubMed, CAS, Scopus and Google Scholar

- Research which is freely available for redistribution 